\section{THEORÍA}

REVISTA DEL COLEGIO DE FILOSOFÍA
NÚMERO 40 | DICIEMBRE 2021 - MAYO 2022 | 211-228

DOI: $10.22201 /$ ffyl.16656415p.2021.41.1696

Traducciones, reseñas y notas

\title{
La dialéctica no es la sofística. Teeteto aprende esto en el Sofista
}

$(\text { Tercera PARTE })^{1}$

Hans-Georg GADAMER

[Continuación de la segunda parte publicada en el número 40, pp. 118-129.

Ésta es la última parte]

[353] Entonces, el extranjero de Elea viene en su ayuda (241c). Y, con ello, empieza la parte filosófica principal de todo el diálogo [Sofista], que está dedicada a analizar y a superar la prohibición parmenídea del no-ser. Este pasaje principal es una parte cerrada que, por el momento, aplaza para más tarde el intento de apresar al sofista. Ciertamente, el joven Teeteto debe ser aproximado a las cosas correctas a través de esta conversación, pero el curso de esta argumentación es sumamente difícil. Sería temerario tratar, en pocas páginas, semejante obra maestra filosófica de un Diálogo pedagógico. Se lee este texto platónico una y otra vez. Todo está lleno de giros sutiles y reticencias. En el trasfondo se escucha a Parménides y uno no puede resistirse a pensar en Aristóteles, quien está llegando a tener gran influencia y a sus comentaristas y, por fin a Hegel, quien resuelve y concluye en gran medida. Y eso que me abstengo de pensar por completo en la lógica moderna cuyas brillantes herramientas elaboraron de la manera más sutil el problema de la predicación y se acercan a este Diálogo platónico como a un manual lógico. Yo percibo mi tarea de una manera muy distinta; se trata, más bien, de desarrollar los argumentos usados en el Diálogo platónico en relación con la fuerza de convencimiento que tengan para alguien que apenas empieza a aprender lo que es un concepto - y esa semejante persona no es, solamente, el joven Teeteto-. No es una tarea fácil seguir la conducción de la conversación por el Eléata, de tal manera que el Diálogo se entienda como un conducir al interlocutor rumbo a

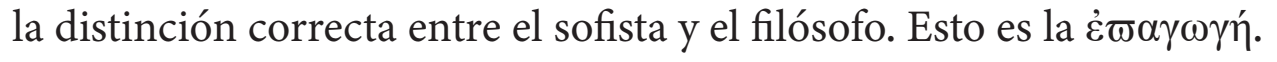

Con todo, Teeteto debe ser conducido hacia la comprensión de lo que es un auténtico filósofo. Ésta es la dificultad más grande con la que él se enfrenta. En efecto, para él es claro que el sofista solamente puede ser un pseudosabio; sin embargo, lo

1 Traducción del artículo "Dialektik ist nicht Sophistik. Theätet lernt das im Sophistes" [1990] (Gesammelte Werke 7: Griechische Philosophie III, Tübingen, J. C. B. Mohr (Paul Siebeck): ${ }^{1} 1991 /{ }^{2} 1999$, S. 338-3 
que es un verdadero filósofo y lo que significa su saber, es poco claro para el renegado discípulo del gran sofista Protágoras y para el joven investigador que es Teeteto. Para él, todos los argumentos de esta índole le suenan como mero pseudosaber. Así, él debe ser conducido por encima de sí mismo y llegar a la confesión de que él mismo no sabe algo de lo que él [354] debiera saber necesariamente. Lo que debe ser la pura ilusión no es comprensible con ello, pero saber esto es indispensable, si se quiere rechazar el pseudosaber del sofista.

Así, la composición del Diálogo está clara, grosso modo. La pregunta clave será: ¿qué significa aparentar? ¿Qué género de apariencia es aquel por el cual el sofista sabe moverse con una similitud fatal a la del filósofo y a la del dialéctico? Será difícil conducir al joven matemático, quien está enfocado, en exclusiva, al conocimiento de relaciones inmutables e invariables de números y figuras, hacia un concepto adecuado del saber y hacia la conciencia de sus propias acciones. Por ello, el camino por el cual el Eléata debe transitar no será fácil. Como lector, entender este camino y acompañarlo, solicita una reducción cuidadosa de lo consabido por todos. Pero, en efecto, esto debe convencer a Teeteto: el no-ser ( $\tau$ ò $\mu$ ஸे őv) no se puede encontrar en sí mismo (238b9-239a9). Haciendo caso omiso de la parte de la investigación que se ha tratado con más frecuencia, quiero narrar la enseñanza que recibe Teeteto.

El Visitante logra hacerle ver a Teeteto que él mismo se ha metido en dificultades ( $\dot{\varepsilon} \vee$ oó 239b5). Teeteto debe reconocerlo. Si él quiere sostener el pseudosaber del sofista, él debe asumir esta dificultad. No puede evitar que con esto faltará a la prohibición eleática que tiene una validez rigurosa en su propio mundo matemático donde, en realidad, no hay ningún movimiento. Por eso, sí le parece raro (ä́oఐov) pero, no obstante, inevitable, enredar el no-ser con el ser (240c1). Con ello, Teeteto mismo cae en la aporía y se siente sin recursos como para contestar a la objeción del sofista, cuando éste le impugna que ni siquiera se podría pensar el no-ser y los "pseudos". El Visitante trata ahora de asistir al joven Teeteto, cuando el sofista se esconde detrás de la imposibilidad del no-ser y, de esta manera, lleva a Teeteto a reflexionar sobre lo que significa el "ser".

La propia inconmensurabilidad del no-ser forma parte de la herencia esencial de la filosofía eleática. No es, como tal, un nuevo tema. Aunque en el curso de la conversación se reconoce como problemático, no tan sólo el pensamiento del noser, sino también el del ser. De esto, uno ya se pudo percatar incluso en el Poema de Parménides, cuando se sostiene a lo largo de tantos versos que los muchos no existen. Tanto al nombrar, como al opinar, como al decir el ser como lo uno, ya existen 
siempre los muchos. Decir el ser nos embrolla en una autocontradicción. Por eso el ser uno se vuelve los muchos. Esto se erige, en lo sucesivo, como el tema. Es un efecto irónico inesperado que el joven Teeteto mismo exigirá preguntar, antes que nada, lo que tò ôv, "el ser" quiere decir (243d3).

Nos encontramos ahora en el punto culminante, crítico, donde la necesidad de preguntar por el ser se vuelve inevitable. Platón subraya [355] este punto culminante, cuando le permite al Eléata externar tres peticiones (241c ss.) y, como tercera, tolerar

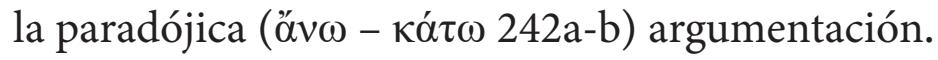

Aquí se piensa en el Parménides platónico. El Parménides representa un verdadero desafío, como es notorio tanto en la tradición antigua como en la mentalidad científica moderna. Uno se pregunta, ¿qué es esto? ¿Una comedia? ¿Un disparate? ¿Misticismo?

¿Sofística? ¿O una pieza de ejercicio elemental de dialéctica? — ¡Y a esto alabó Hegel como la más grande obra de arte de la dialéctica antigua!- - Ahora, la crítica a Parménides en el Sofista platónico, de la cual se trata aquí para nosotros, no es un juego igualmente problemático como el Diálogo Parménides. No obstante, el estilo de argumentación del Visitante de Elea es comparable, en especial, cuando se varían más los grandes géneros (además del "ser", conceptos como "movimiento" y "reposo" y "conceptos de reflexión tan formales" como la identidad y la diferencia). Así es válido escuchar la lógica latente del mensaje de Elea. Por lo tanto, parece bien motivado, porque la conversación debe dirigirse hacia el concepto del ser de Parménides. En la relación inconcebible entre el ser y el aparentar, entre la aparición, la ilusión y la apariencia, se esconde un entrelazamiento entre el ser y el no-ser. Tal vez detrás exista incluso la relación casi insoluble que ya permea al Poema de Parménides, a saber, la relación entre el saber divino y el saber y opinar humanos. Parménides lo compuso en versos homéricos. De manera similar, la crítica del Sofista por parte del Eléata, parece casi como una obra puesta en versos a manera de diálogo. El propósito será seguir el curso de la conversación y ejecutar el paso del opinar convencido que se atiene al noein eleático hasta el logos platónico. La conversación toma su curso cauteloso para hacer conscientes las opiniones fijas y los prejuicios vigentes en el interlocutor, y vencer sus resistencias paulatinamente. ${ }^{2}$ Quien trata de transformar en argumenta-

2 Una nueva contribución de C. D. C. Reeve (1985) da una buena vista panorámica en las investigaciones re-

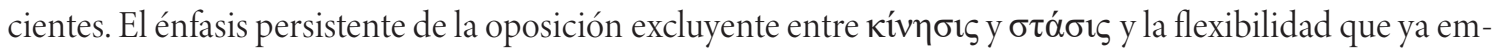
pezó en la comparación entre los Materialistas y los Amigos de las Ideas, aparece en el análisis cuidadoso, no como el gran trabajo a través del cual en boca del Eléata conduce a alguien a la comprensión de la dialéctica, 
ciones concluyentes lo que llega a discutirse ahí, no entiende ni siquiera la mitad de lo que está pasando y lo que el texto nos da a entender.

Hay que ver cómo el joven matemático se ve forzado a la reflexión. La fijación del problema del sofista parece imposible sin el paso hacia el concepto. Este paso, aparentemente, aún no se efectuó con los antiguos que trataron de distinguir $\tau \grave{\alpha}$ őv $\tau \alpha$ [356], cuántos y qué tipos hay (242c). El Visitante mismo caracteriza como "mito" lo que antes se decía del ser, aparentemente porque, en este caso, el sentido de ser se presupuso como algo sobrentendido. Prima facie, parece como si tuviéramos una primera doxografía delante de nosotros, a saber, una sinopsis de las enseñanzas de los otros, la que Platón pone en boca de su conductor de la conversación como uno que sabe. Algo similar lo conocemos de los escritos tardíos de Aristóteles, a través de los cuales Aristóteles domina, desde Teofrasto, la tradición completa de la filosofía griega. En realidad, la doxografía de Aristóteles es algo muy distinto de esta sinopsis platónico-eleática. Aristóteles aplica, simplemente, su teoría de las cuatro causas a sus predecesores. Esta teoría la había desarrollado en la Física y para la física (Física B7), y desde ese fundamento acomete la conceptualización del sentido del ser en la Metafísica. Platón no aplica ninguna teoría. En efecto, él deja al Eléata seguir un esquema pitagórico y pregunta por el número del ser. La verdadera pregunta por el ser la deja aflorar, paulatinamente, del análisis crítico de los antiguos. El interlocutor se encuentra lógicamente perdido, ya que es incapaz de manejar los valores ontológicos del ser y del aparentar. Sin embargo, él deja ver que conoce a fondo el Poema de Parménides, al igual que las teorías de los fisiólogos jónicos, contra los cuales se dirigió la crítica eleática. La sinopsis constructiva sobre las teorías antiguas sirve, en verdad, para percatarse de que el "ser" debe ser un tercero, sin importar que sea uno o muchos (243e2).

En esta conversación, Teeteto desempeña un papel más bien modesto. Sin embargo, no es un mero seguir aferrado a la forma del diálogo, donde, en realidad, estaría indicada una exposición didáctica. ${ }^{3} \mathrm{El}$ juego a base de preguntas y respuestas que el Eléata juega con Teeteto, parecerá bastante elemental. Pero, en verdad, ahí surge algo decisivamente nuevo, a saber, la forja del concepto y del dar razón a través de

sino como una trampa (trap), y el juego entre la identificación y la predicación de parte de Platón como su propia confusión. Asíse aparece a la filosofía cuando uno la contempla por sus resultados como una ciencia que ella no es.

3 Entretanto, también se tomó en serio el acontecer dialógico para el Sofista, por ejemplo, en Seth Benardete (1984), quien, en efecto, no tiene en mente a Teeteto, sino a Sócrates. 
la dialéctica, para lo cual Teeteto todavía no está en condiciones. El problema es en Platón bien conocido. Se trata del paso de las opiniones (las $\delta o ́ \xi \alpha \imath$ ) hacia el logos. En el Poema de Parménides esto fue apenas una coexistencia y se introdujo como una revelación divina que le deparó la fortuna al elegido.

Traté de mostrar en mis contribuciones al Poema $a^{4}$ de qué manera, no obstante, se insinúa el paso hacia [357] el concepto en el uso del singular $\tau$ ò öv. Igualmente subrayé que, en el Poema, ni siquiera existe el singular de $\delta o ́ \xi \alpha$. El camino hacia el concepto aún no prosperó hasta poder ver reunidos los muchos en el uno. Platón es muy consciente de esto y por eso son solamente pasos ligeros y cautelosos que el Eléata exige al joven interlocutor para conducirlo al camino hacia el concepto.

Del examen crítico resulta, mientras tanto, que la teoría eleática del "ser uno" no se puede sustentar. Teeteto sí trata de salvar todavía el ser uno como el sentido de dos nombres para el uno (244c-d). Pero esto permanece igualmente infructuoso como el supuesto ser total del ser. Así resulta que no es más fácil entender el ser que el no-ser (246a). El camino hacia el concepto aún parece ser pedregoso - pero sí se dio un primer paso en este camino cuando el "ser" no se piensa como siendo uno ni como dos, ni como un todo, ni como un no-todo-. Ya no es un contar mitos. El concepto se atisba.

Otro paso más en este camino se avecina ahora en la transformación de la puesta en escena, cuando se narra la lucha titánica entre los Materialistas (que casi se podrían denominar heraclíteos), y los Amigos de las Ideas (246a ss.). ${ }^{5}$ Uno supone que ambas posiciones son extremas que, en el fondo, ya implican un concepto del ser. Esto indica la unilateralidad de esas posiciones, la cual aflora de la conversación. En realidad, no será posible que el cambio incesante del llegar a ser y la constancia intangible del orden de las ideas y de los números, pudieran constituir un antagonismo irreconciliable. Ya que se trata de una "gigantomachia", estaremos a la expectativa ante cuál será la decisión definitiva. Así también sucedió en la gigantomachia mítica de Hesíodo y su repercusión en el drama de Prometeo de Esquilo, donde ambos centran la atención en el fundamento del dominio duradero de Zeus Olímpico. Estaremos preparados para que no sucumban tan sólo los Amigos de las Ideas, sino también para que la intención sea una auténtica reconciliación entre los contrincan-

4 Cf. las contribuciones reunidas bajo el título "El Poema de Parménides", en el volumen 6 de las Obras reunidas, pp. 30-57, como también en "Parménides o el aquí del ser", en este mismo volumen, pp. 3-31.

5 Cf. también para eso "Platón y los presocráticos" en el Volumen 6 de las Obras reunidas, pp. 68ss., así como "El Parménides platónico y sus consecuencias", en el Volumen 7, p. 319s. 
tes. En realidad, no se narra la posición de los Materialistas en el sentido crudo sobre el cual ya en el Teeteto se le había encubierto una teoría del movimiento altamente refinada. Ahora, en el Sofista, el joven Teeteto está en el acto dispuesto a confiar en que los Materialistas puedan hacer las rectificaciones correspondientes. A ojos vistas, la lección que Teeteto había recibido de Sócrates ya rindió sus primeros frutos. El ser del movimiento y del llegar a ser diferente adquirieron preponderancia para la pregunta por el ser verdadero.

Por cierto, llama la atención que Teeteto describe a los Amigos de las Ideas con un "nosotros" - así tan abiertamente el joven matemático pertenece a ellos-. También [358] hay que fijarse en que Teeteto da su beneplácito sólo de manera titubeante cuando se conduce la cinética universal a su concepto común, a saber, al concepto de la dynamis (247e). De manera similar aparece en 248c10. Ahí Teeteto persiste en su mundo de ideas inalterable, y cuando le exigen el concepto de la "dynamis", el Visitante no puede conseguir su beneplácito en lo absoluto. Él debe, por lo tanto, desistir del argumento de la dynamis (248e) y tiene que recurrir a un argumento ad hominem. Es que el ser no podría estar rígido y exánime (249a). Entonces, también el Amigo de las Ideas debe admitir la movilidad, porque la vida y el pensamiento sí existen. Ambas posiciones, por lo tanto, son insostenibles.

Así, finalmente, parece difícil la elección entre ambos lados opuestos. Se quiere hacer como los niños cuando ellos deben elegir. Quisieran, de preferencia, "ambas" cosas. Pero ahora el llegar a ser móvil y el orden intangible parecen excluirse mutuamente. Lo palpable de la experiencia de la realidad y la intangibilidad de las ideas inalterables no contienen una respuesta satisfactoria a la pregunta qué, en realidad, quiere decir el "ser". Pero esto significa que el sentido del ser entre el movimiento inteligible y la intangibilidad incomprensible es, de igual manera, tan poco claro como el no-ser (250c9). Si el ser es o móvil o inmóvil, ¿qué ser, después de todo, aún habrá? ¿Hacia dónde se podrá dirigir la mirada? ¿Habrá un tercer ser? (250c1). Esta frase, Heidegger la habrá tenido muy presente en aquel entonces cuando se le presentó la pregunta [que interroga] por el ser. Aquí la frase introduce el paso que por fin nos conduce al pensar del "logos" (y del ser como del logos). Si ambos, el ser y el no-ser, son de igual manera incomprensibles, se da a entender su unión inseparable, a saber, su relación de correspondencia (251a). La relación es, no obstante, la estructura del logos mismo. Éste es el nuevo horizonte, en el cual la legitimidad de la dialéctica se probará en su justa medida. Aquí Teeteto, de nuevo, tiene grandes dificultades para comprender. 
Se ve cuán difícil es obligar, al matemático Teeteto, a la reflexión sobre sí mismo. Él todavía sigue sin entender qué es el "logos”. El Visitante de Elea empezó muy hábilmente a tematizar la relación entre ser y no-ser e introdujo, de esta manera, el concepto de "logos", el cual, Teeteto, gracias a su ciencia, conoce a fondo, como término matemático (para "proporción"). Pues, trátese de lo que se trate, naturalmente, la relación entre dos cantidades es independiente de las constantes que están relacionadas entre sí; que se trata, en realidad, de una unión, o sea, de aquella relación, la que se presenció continuamente en la conversación. ${ }^{6}$

[359] No obstante, primero se le debe aclarar a Teeteto, con un ejemplo, lo

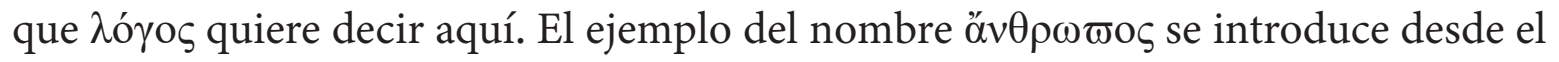
punto de vista formal, a saber, que el uno se vincula con muchos atributos posibles (251a-b). Con ello casi se atisba algo como una teoría categorial platónica. Un uno

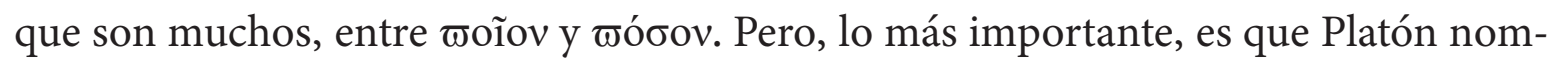
bra aquí, explícitamente, además del av̉ió, el hombre mismo, en el mismo sentido

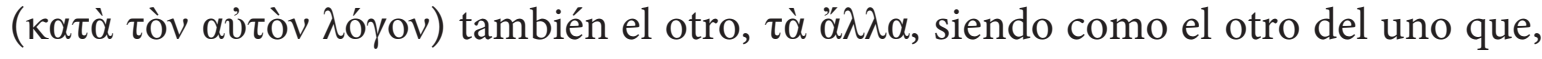
simultáneamente, es lo mucho. En otras ocasiones, conocemos en Platón la expresión

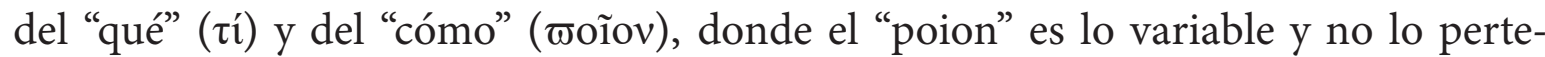
neciente a la esencia. Pero aquí se aclara explícitamente que incluso esta distinción original de $\tau$ í y woĩov se debe tomar totalmente como forma, y esto quiere decir: intercambiable, así que se puede preguntar tanto por la esencia del "qué" como por la del "cómo". En Platón, sin embargo, esto se expresa de la siguiente manera: signifique lo que signifique el ser, la ov̉oía, necesariamente debe ser algo que se le pueda adherir a todo lo que es y que pueda estar ahí junto con él. Esto no es, en lo absoluto, la teoría

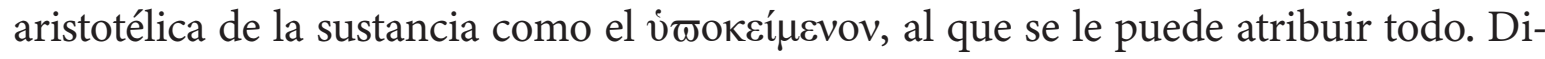
cho en conceptos aristotélicos, el "ser" es más bien ఐpós $\tau$, un término que aún no se

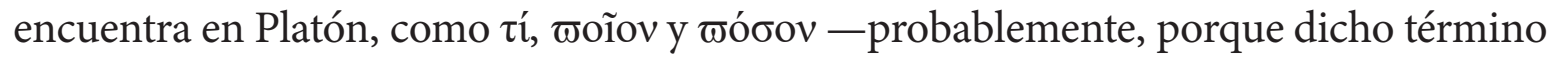
es omnipresente.

Así se gana un acceso universal, y esto también se hará explícito (251c-d).

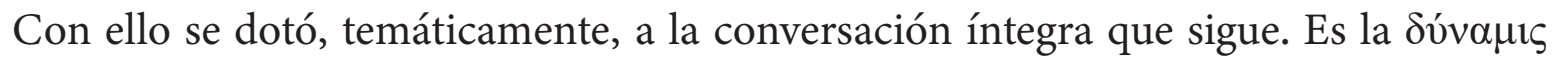

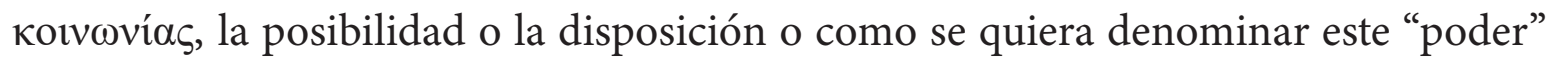
de estar reunido que se manifiesta en el $\lambda$ ó $\gamma$ os. En realidad, aún no es un conocimien-

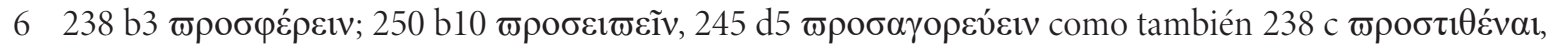

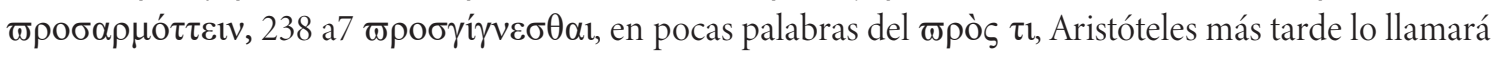
así, se habla constantemente.

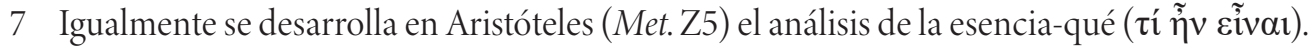


to verdadero de la esencia del $\lambda$ ó $\gamma$ o $-\mathrm{y}$ de hecho, Teeteto permanece muy decidido en un punto-: "Pero, en todo caso, el movimiento y el reposo no pueden estar juntos simultáneamente" (252d). Esto el Eléata se lo concede deprisa y con insistencia sospechosa. "Después de las necesidades más apremiantes" esto sería imposible. Entretanto, permanece como vínculo el ser ( $\tau$ ò öv), que se puede enlazar con todo. Ciertamente, no se puede enlazar todo con todo. Esto, el Eléata, lo admite inmediatamente. Se nota cuán cautelosamente él prepara al joven matemático para la verdadera esencia del logos, a saber, la sinopsis y la distinción. Paulatinamente se acercan bajo la palabra clave "los más grandes géneros", "kinesis" y "stasis" (y con ello, por fin, incluso la física y la matemática, a lo que también se alude en el Filebo (26d) en el tercer

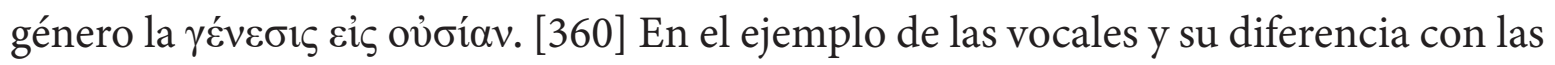
restantes letras del alfabeto se ilustran los géneros omnicomprensivos. No se tratará de un ejemplo discrecional, cuando aquí se hace referencia al alfabeto. La escritura alfabética es, en verdad, una producción abstractiva enorme que le da al concepto del saber un cuño específico, como el conocimiento de la escritura y el arte de la armonía musical. En estas dos áreas se trata, evidentemente, del dominio de un asunto que estriba en una diversidad estructurada que se conoce a fondo. Llama la atención que en este conjunto de ideas y por primera vez en esta conversación, aparece el concepto de los $\gamma \varepsilon \dot{\varepsilon} \eta$, de los géneros, y esto de ahí en adelante se conservará. Como en estas habilidades de la escritura y de la música, también en la esfera de acción universal de la conversación correcta, a saber, en el dominio de los logoi, se señala el respectivo conocimiento como la ciencia más importante y omnímoda y se le asigna, expresa-

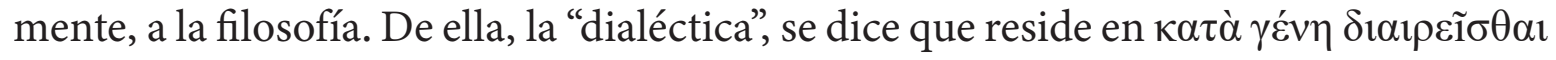
(253d). Esto significa que las palabras y los conceptos no se exponen como $\varepsilon$ ไ $\delta \omega \lambda \alpha$ $\lambda \varepsilon \gamma o ́ \mu \varepsilon v \alpha$ (234c6), sino que en ellos se pueden hacer distinciones que se estructuran lógicamente y conforme a la realidad.

Sea como sea que uno se explique en detalle la descripción muy discutida del saber dialéctico del filósofo (253b), de todos modos, ella describe la verdadera dialéctica en vez del mal uso del lenguaje para la prestidigitación erística que caracteriza al sofista. Esto se acentúa con firmeza (254a). Cuando uno se esmera en buscar la esencia del sofista, se experimenta cómo éste se refugia en la oscuridad del no-ser. A esta dificultad de encontrar al sofista le corresponde otra dificultad similar, cuando se trata del filósofo. De él se dice que también es difícil reconocerlo, porque se encuentra en la demasiada claridad del ser. A lo que se quiere aludir con esto, apenas se insinúa. Por ventura, en este conjunto de ideas, se dice que la mayoría de los hombres vive en 
tal cautiverio (253c7) que no son capaces de levantar los ojos a lo divino (254b1). No se comenta nada más a este respecto. En realidad, la tarea no consiste en buscar al filósofo, sino al sofista quien se encuentra en la oscuridad del no-ser. Pero no se necesitará ser un visionario para captar la ironía en esta separación entre el tema del sofista y el tema del filósofo. Como si se pudiera decir lo que distingue al filósofo del sofista y al ser de la ilusión, sin que se conozca a los dos, la ilusión y el ser. En el camino hacia la profundización en los más grandes géneros del ser que a Teeteto le parecen obvios, pero que a nosotros nos parecen extraños debido a su aparente disimilitud, se logrará adjudicar al no-ser algo del ser para que hasta el interlocutor vacilante lo pueda consentir (256b8). Con ello se abre, sin duda, un nuevo horizonte. La compatibilidad entre el movimiento y el reposo, entre el llegar a ser [361] (esto es, la alterabilidad) con el ser (esto es, la permanencia), será la nueva comprensión determinante. La verdad es que no se sigue de cerca lo que esto significa, pero uno pensará en el acercamiento recíproco entre ambos adversarios en la batalla de gigantes. Debido a la intangibilidad de la phronesis, unos entendieron el ser como "dynamis" y los otros exigen a los Amigos de las Ideas el reconocimiento de la vida y del nous y, con ello, del movimiento. Si se reconoce ahí el movimiento y la conciencia en la unidad de la vida y el alma, entonces, se recuerda también que la misma construcción del alma del mundo en el Timeo determina la estructura entera de la cosmogonía. ${ }^{8}$

En todo caso, la objeción del sofista se vuelve superable. Con ello, sin embargo, todavía no se soluciona la tarea de distinguir al sofista del filósofo, aunque se pueda justificar al final el entretejimiento del ser con el no-ser y la ilusión. Hasta el final de toda la conversación se hará ver que con ello el abuso del sofista, pero también el carácter verdadero del dialéctico, aún no se habrán entendido completamente. Para ello, solamente se cumplió con una condición previa, que es la expulsión del mal uso sofístico de la tesis eleática, a saber, que no se puede ni pensar ni decir el no-ser. Para pescar al sofista, se tendrá que dar otro giro a esta conversación, como se mostrará más tarde.

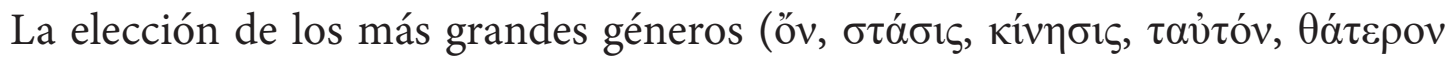
255 d ss.) parece, en cierto modo, arbitraria. Lo que ellos deberían ser se evidencia, ciertamente, por la analogía. Deberían ser como las vocales del ser. Las vocales no significan nada por sí mismas, sino que ellas posibilitan solamente sílabas, palabras

8 Para las relaciones entre el Timeo y el Sofista, ver mi estudio "Idea y realidad en el Timeo de Platón", Obras reunidas volumen 6 , p. 249 ss. 
y oraciones, que tengan cierto significado, de forma que representan el vínculo de toda conversación. Cuando se nombran los más grandes géneros, esto parece significar lo siguiente: pueden estar con todo - como también los números pueden estar con todo, sea lo que sea con tal de que sea tanto y otro tanto-. El estar con algo de esos más grandes géneros no es, de este modo, que se tenga aquí un género máximo general, como el uno que se diferencia de diversas maneras y que se especifica cada vez más. Por el contrario, lo que aquí son los más grandes géneros tiene otra índole

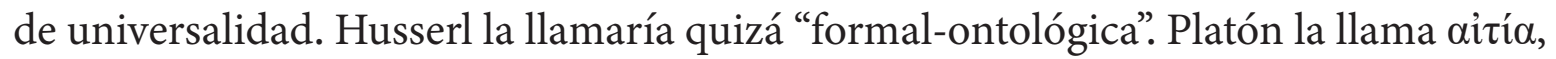
causas del todo. Como éstas son capaces de unir todo, son el enlace, como las vocales. Tampoco el ser (ov̉oía 250b9), se introduce aquí como el género máximo. El ser está también aquí entre otras cosas aun cuando sea con todo, como la mismidad y la diferencia está con todo ente, lo que más tarde se manifestará. Pero obsérvese que también aquí hay movimiento y reposo, alterabilidad [362] e inalterabilidad y, en efecto, con el ser, el ôv, se acepta como algo que corresponde a todo y une todo. En este conjunto se vuelve a notar cómo, el Eléata, toma en consideración la opinión previa de su interlocutor. Pero uno se pregunta qué pudo mover ahora a Teeteto a concordar, después de que él siempre sostuvo lo contrario. Aparentemente, él llegó, en el seguimiento de los pensamientos del Eléata, por lo menos tan lejos que entiende que el ser puede combinarse con todo, con la alterabilidad y con la inalterabilidad. Lo que significa el hecho de atribuir ser al movimiento, su no-ser, seguramente aún no lo entiende del todo. Supuestamente, él sigue pensando todavía de la misma manera con la cual defen-

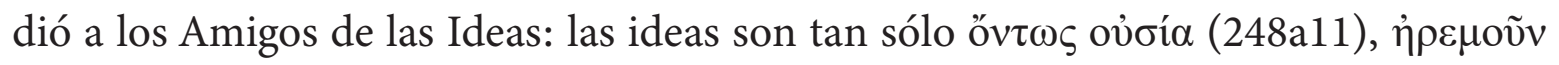

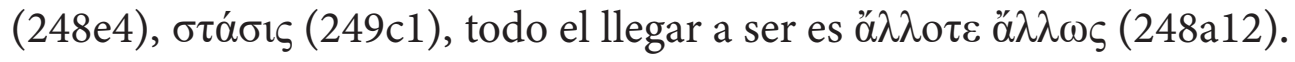

Lo que yo quiero decir la mayoría de las veces con "ser-con", el Visitante de Elea lo parafrasea, al principio, como "mezcla" ( $\mu \tilde{i} \xi 1 \varsigma)$ e introduce después, paulatinamente, la expresión platónica de la $\mu \varepsilon \dot{\varepsilon} \theta \varepsilon \xi 1 \varsigma$, de la participatio, la participación. En Platón, también esta expresión se intercambia, a menudo por otras expresiones, como mezcla, comunidad estar ahí, etcétera. La "participación” y la "cooperación” no significan aquí un tener o un tomar, sino un ser. ${ }^{9}$

Si se trata aquí del "ser-con" del único concepto, de una idea con la otra o si se trata del ser-con de la idea, en cada caso con un ente particular o si se trata del sercon con la idea de la psique, a saber, con el cognoscente, se distinguen con razón

9 El tema de la $\mu \varepsilon \dot{\theta} \theta \varepsilon \xi 1 \varsigma$ se encuentra, desde 1930, frecuentemente en mis estudios de Platón. De igual manera, en especial, recientemente también en "Platón como retratista", en este volumen 7 p. 245ss. 
estas tres aplicaciones de los conceptos en Platón ${ }^{10}$ —de todos modos, se trata aquí de una relación estructural universal sui generis-. Uno no puede describir esto ni con el hacer ni con el padecer, ni con el imitar o lo que sea, como si estos géneros fuesen ámbitos propios del ser. Estos géneros no son así. Ellos son aĩía. Así también se dice, por ejemplo, de la movilidad que ella es "diferente de la diferencia" (y de igual índole que la mismidad y que la stasis, 256c5). Por el otro lado, todo ente es algo diferente. Cada ente participa de la diferencia, en cuanto que no sea otra cosa. La naturaleza de la diferencia se muestra distribuida de diversas maneras como la ciencia ( $\kappa \theta \theta \dot{\alpha} \varpi \varepsilon \rho$ $\dot{\varepsilon} \varpi 1 \sigma \tau \eta ́ \mu \eta ~ 257 c 8)$. Resulta así (258e) que la diferencia no es otra cosa que el ser de lo diferente en su propia distribución. Sólo en este sentido está implicada la diferencia con todo lo diferente. De nuevo, esto es más que una pura comparación cuando aquí se compara la diferencia con las ciencias. De esta manera, la diferencia está aquí con todo lo diferente y no en otra parte, del mismo modo como [363] la ciencia quiere decir que uno puede diferenciar en cada caso o, como suele decirse en nuestra lengua, que uno sabe de lo que se trata. Se debe atener a que esos "más grandes" géneros deben ser pensados de una manera trascendental, o sea, no según el orden del género y de la especie. Más que nada deben ser aquello que, después de todo, hace posible toda diferenciación, especificación, identificación y, con ello, todo el saber y el conocer, como las

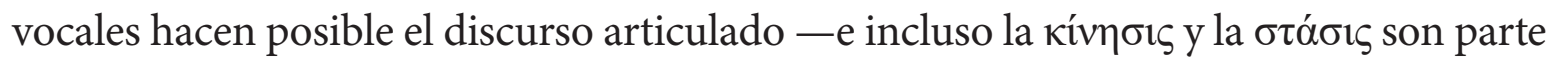
de esto-. Estas constataciones se vuelven significativas para un siguiente paso.

A saber, el Visitante muestra que el logos como tal, en el cual se entremezclan todos estos "más grandes" géneros es, por lo tanto, también un "género" omnímodo, un gran género propiamente dicho. Sin él no habría, ni siquiera, filosofía (260 a). De nuevo Teeteto apenas entiende qué es, en realidad, lo que se quiere decir con esto (ov̉к ع̈ $\mu \alpha \theta$ ov 260b4). Primero se le debe mostrar que en el logos y en la doxa, literalmente, pululan el no-ser y el engaño y la apariencia falsa (260c8). Esto se le aclara con la ayuda de la distinción de conceptos gramaticales entre el sustantivo (övo $\mu \alpha)$ y el verbo $(\dot{\rho} \tilde{\eta} \mu \alpha)$.

Con este análisis gramático-estructural del logos se marca el paso decisivo con el cual Platón supera a Parménides. Ciertamente, ya el Poema refleja la inseparabilidad del "ser" y del "noein". Ella corroboró ahí lo que Parménides nunca perdió de vista, a saber, que el ser es "presencia". Pero ahora se muestra: nombrar todavía no es decir. Las palabras yuxtapuestas todavía no son ningún discurso que detalla algo

10 Ver Ernst Hoffmann (1918). 
y lo hace manifiesto ( $\delta \varepsilon \lambda \circ \tilde{v} v \tau \alpha 261 \mathrm{~d}-\mathrm{e})$. Una afirmación se da, tan sólo, cuando al övo $\mu \alpha$, al "sustantivo", no le falta el $\rho \tilde{\eta} \mu \alpha$, el verbo. ¿El tiempo? Como en la traducción al alemán de $\dot{\rho} \tilde{\mu} \alpha$ como "palabra de tiempo", se escuchaba, indudablemente, en los vocablos griegos el fluir, de las palabras, por tanto, la kinesis y, con ello, también el tiempo. A Teeteto, quien sólo está acostumbrado al trato con los números, le parece todo esto, por lo visto, bastante ininteligible. Se repiten respuestas del tipo: “¿cómo?”, "esto no lo entendî" (Sofista, 262ss.). El logos es aquí, precisamente, otra manera de seriación distinta de la progresión aritmética. No se trata, tan sólo, del hecho de que el logos incluye o excluye la concordancia de dos ideas; también existe en ello la maduración de la declaración misma que en el ejemplo dado se refiere al mismo Teeteto, a este hombre lanzado en el tiempo.

Cuando ahí se dice "Teeteto vuela", uno no puede dudar de que esto es erróneo, porque Teeteto es un hombre y no un pájaro. La incompatibilidad de la idea de hombre con la idea de volar aclara que aquí se expresa algo imposible, no precisamente algo incorrecto aun cuando, indudablemente, también es incorrecto. Por ello también se le agrega de manera explícita a este "Teeteto vuela" que "él está sentado aquî" para, en cierto modo, distinguir lo imposible de lo incorrecto. También esto podría ser falso, que Teeteto está sentado aquí. Naturalmente, podría también estar de pie frente a su interlocutor. No en balde [364] me parece que esta oración "Teeteto

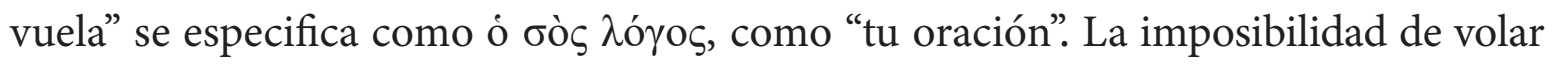
corresponde a este uno de igual manera que lo correcto o lo incorrecto del estar sentado o parado. Le corresponde a este uno como a todos los otros. Su ser hombre, con todas sus posibilidades esenciales e imposibilidades, es lo suyo. Es éste, Teeteto, quien está sentado ahí. Ésta es, por lo tanto, la función del ejemplo elegido para el verdadero acto de pensar de la conversación, a saber, el conducir a Teeteto quien ya se cansó del arte de las disputas vacías. Si él aquí cita el escrito de Protágoras acerca de la lucha en la plataforma, ciertamente no lo hace con entusiasmo Sofista, 232d). Con ello gana un valor informativo especial el giro que la conversación sobre el logos tomó como un género.

La transición gramatical del conjunto de ideas hacia la relación constituida por el conjunto de onoma y rhema, da un paso verdaderamente importante (261d). La naturalidad de la participación del individuo en la idea, o, mejor dicho, en la presencia de la idea en el individuo se ilustra con esto. Ella está incluida en todo discurso y, ni siquiera, constituye, por lo tanto, un tema especial de la dialéctica. Está atada a la experiencia vivencial, la cual nunca puede ser alcanzada por los "mathemata", el saber aprendible. Si es este Teeteto y si él está sentado o parado, habrá que verlo. Eso no se 
puede saber, de la manera en que se sabe que un hombre no puede volar, independientemente si es este individuo $u$ otro. ${ }^{11}$

Y, oh sorpresa, de repente, se ve que el pseudo, cuya prueba Teeteto no pudo lograr en la conversación con Sócrates, (en el Teeteto) se demuestra en él mismo. Él reconoce en el ejemplo consigo mismo que incluso la mezcla de percepción y opinión puede ser falsa (264b2) y, de esta manera, el poder ser falso de una afirmación o de un logos es, con mayor razón, incontrovertible. El subterfugio del sofista se frustra. El último paso para apresar al sofista ya puede empezar.

Recordemos cómo, al principio de la conversación, la figura del sofista, ya claramente visible, parece evadirse de nuevo hacia lo impalpable, porque la diferenciación entre el discurso reproducido y el simulado llegó a estancarse completamente por los acertijos sin solución de la imagen y el simulacro. Ahora, después de todo, ya dejamos atrás la objeción del sofista de que ni siquiera puede existir un simulacro. Así se puede ver con facilidad que en el caso del sofista se trata, exclusivamente, de una apariencia falsa, por lo tanto, de una prestidigitación ( $\varphi \alpha v \tau \alpha \sigma \tau \iota \kappa \eta ́)$. Vimos que incluso, para el Visitante de Elea, [365] - y no tan sólo para el joven Teeteto- fue difícil distinguir entre la imagen y el simulacro, la apariencia tan similar del filósofo y del sofista, ya que ambos tienen que ver sólo con los logoi. También ahora, el Visitante de Elea prepara cuidadosamente a Teeteto para que sea comprensible la asignación de la apariencia meramente falsa a las reproducciones humanas en contraposición con las imágenes divinas. Así introduce la acepción de la diferenciación fundamental entre la imagen y el simulacro, la diferencia más próxima del arte, que despierta la apariencia de saber.

Con ello se consuma el último giro decisivo para apresurar al sofista, el cual deja atrás la esfera del $\lambda$ ó $\gamma o c$. De la serie de las demás diferenciaciones, el Eléata dice que para esto nos hacen falta, generalmente, los nombres (267d). Ésta es una indicación importante, de que nos movemos hacia una dirección, a la cual no le otorgamos, seguramente no por casualidad, la correcta atención. Por último, sólo este giro nos conducirá a la real diferenciación entre el filósofo y el sofista. Que para esto ni siquiera haya los nombres calificativos, hace comprensible de qué manera el desconocimiento de la verdadera dialéctica y su confusión con el mero simulacro de la erística estuvieron muy difundidos. Lo que llevó a la victoria del movimiento sofístico, en realidad, no fue otra cosa sino una confusión generalizada. Su aclaración no se puede sustentar

11 Recuerdo numerosos estudios agudos en relación con el "Teeteto volador" (algunos ejemplos se mencionan en el volumen 6 de las Obras reunidas, p. 147 s, inciso 24). Que se ponga a prueba mi solución "sencilla". 


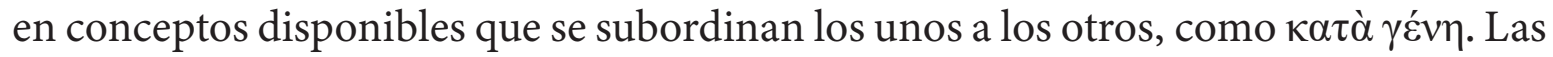
distinciones aquí brillan por su ausencia (267d5). Es que aquí se trata, incluso, de una diferenciación cuya datación es anterior a nuestros conceptos. Es la cuestión acerca de que si se sabe o por ignorancia se simula la apariencia de saber. En todo caso aquí ya no se trata de una imitación por el discurso, sino de una autopresentación. La diferencia no reside en los argumentos, sino en la intención de quien argumenta de tal manera. Sólo por ello se puede diferenciar al filósofo del sofista.

Aristóteles entendió perfectamente bien este punto cuando él en el libro $\Gamma$ de la Metafísica distingue entre el sofista y el dialéctico (lo que él así denomina) tan sólo

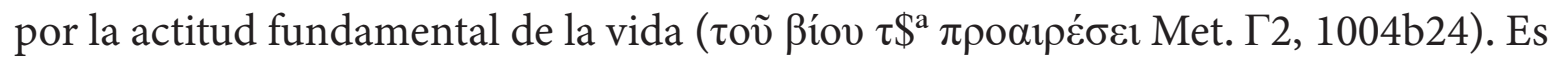
precisamente ella la que destaca al dialéctico, quien busca la verdad, frente al sofista. Esto confirma el final de la conversación platónica. No son los argumentos más fuertes a través de los cuales, finalmente, se logra la diferenciación. Se logra por el caminar juntos en el transcurso de la conversación que el Eléata condujo. Él acerca al matemático escéptico tanto al asunto que, en el futuro, este último ya no sucumbirá a la apariencia falsa. Por lo tanto, él también, en adelante, será capaz de dar cuenta de lo que quedó a deber en la conversación con Sócrates. Ahora sabrá mejor lo que son el logos y el saber verdadero, y cómo se distingue del simulacro sofístico.

Lo que la escritura acerca de la ciudad ideal elevó, a grandes rasgos, al tema principal, a saber, el auge de la dialéctica, pasando por la matemática (República VI), [366] aquí, no tan sólo fue anunciado, sino que se consumó en la persona de Teeteto y a la vista del lector de este Diálogo. La conducción, a través del Eléata, fue de ayuda. Tanto Teeteto como el lector dejan pasar de una manera inteligente los prejuicios reinantes acerca del sofista cuando ahí ven caracterizado al sofista como el pescador con caña y el cazador de los hombres, o como comerciante con saber o como puro prestidigitador. Él ha aprendido a ya no incurrir más en la mera apariencia como si no dependiera de otra cosa más que del arte de argumentar. Esto sería caer, una vez más, en la confusión entre el sofista y un verdadero filósofo que busca la verdad en el claroscuro de la pregunta y la respuesta. Está convenido de que ambos se parecen, pero como el lobo y el perro (231a6). Al final, Teeteto lo sabe, y no tan sólo porque acaba de aprender a definir al sofista, sino también porque lo aprendió a distinguir, a través del caminar con el Eléata, en esta conversación.

Con ello se abre una dimensión completamente nueva a la de los logoi como tales, aquella de dejar que aparezcan estados de cosas, verdaderos o falsos. A estos artistas de la elocuencia no les importa, en lo absoluto, la verdad. Platón llama a esto 
el imitador que disimula y distingue, de nuevo, entre las dos formas de este imitador quien disimula, a saber, de estos ignorantes que se presentan como sabios sin que sean por eso impostores o mentirosos. Por un lado, a éstos pertenece el demagogo quien vive del aplauso y está, por así decirlo, extasiado. Él queda a merced de aquello que el arte de la elocuencia le adjudica. Es lo que el Gorgias caracteriza como adulación (Gorgias 463b, 501c). Por el otro lado, es el sofista quien quiere aparecer victorioso en la discusión y la argumentación y quien quiere tener siempre la última palabra. Ambos, en realidad, no pertenecen a la dimensión de los logoi que dan cuenta pensante con tal de que sus discursos sean una imitación del saber y un simulacro en la apariencia del saber. Su discurso tiene, tan sólo, una apariencia ilusoria y queda, en verdad, reducido a nada. Al final de este largo rodeo, a través de este reconocimiento del "no", el Visitante de Elea llama la atención sobre la apariencia y nulidad de la sofística, esta falsa apariencia de la dialéctica verdadera.

En efecto, se debe mirar hacia antes de Parménides o, pasando por Hegel, hasta Nietzsche, si se quiere, de nueva cuenta con Platón, tomar realmente en serio la pertinencia de la futilidad de la apariencia en relación con el ser. Esto es si ya no se piensa alejarla de sí mismo con la ayuda de la "ciencia" como un mero desconcierto. En una reasunción de la radicalidad de Nietzsche, Heidegger intentó, desde allí, dar un paso hacia atrás y, precisamente con ello, dio un paso hacia delante. Él reconoció los límites del pensamiento griego de la aletheia y, con ello, la fuerza creadora que emanó de este origen griego del pensamiento para la civilización universal de los nuevos tiempos.

[367] Mi propio interés por el Sofista y, en general, por la obra de los Diálogos platónicos está motivado, sobre todo, por la discusión que Heidegger suscitó acerca de la metafísica y, en particular, bajo la palabra clave "la superación de la metafísica". En sus trabajos tardíos, el paso largamente preparado de regresar hasta antes de la ontología aristotélica tuvo como consecuencia que Heidegger tratara de escuchar y se atreviera a pensar ciertos atisbos y huellas del pensamiento inicial de los griegos, sacados de las ruinas de la tradición presocrática. Puesto que nuestras exposiciones están influenciadas por Aristóteles, es éste un trabajo ímprobo que tal vez sólo con vehemencia se pudo solucionar. En realidad, Heidegger se atrevió a hacer algo muy inusual, a saber, evocar una tradición ágrafa, o sea, los tiempos prehistóricos que se manifiestan, exclusivamente, en la repercusión del idioma griego, de sus palabras y sus palabras primitivas; las midió, paso a paso, como un veedor de agua que busca venas de agua ocultas. Esto provoca que sus estudios acerca de Anaximandro, Parménides 
y Heráclito sean significativos para su propio camino, tan actual y orientado hacia el futuro. Ellos, sin duda, nos dejan perplejos por la osadía de la interpretación de sus textos fragmentarios. La primera tierra firme que nosotros podemos alcanzar con un interés análogo me lo proporciona, a mi juicio, la obra de los Diálogos platónicos. La concepción de la idea en Platón no me parece señalar el paso hacia la metafísica aristotélica, de la manera como Heidegger describe a Platón, y, como Heidegger dice, haber introducido, por este giro, el abandono del pensamiento de la "aletheia", la verdad, hasta la mera rectitud, la ỏ $\rho \theta$ ó $\rceil$ s. Este "giro hacia la idea", entendido por Heidegger como la preparación de la metafísica aristotélica, de todos modos, no se encuentra, justamente, en el Sofista, el cual, como es sabido, se entiende por muchos de manera precisa como un apartamiento de la teoría de las ideas. El curso de Heidegger en Marburgo, en 1924, acerca del Sofista, que sólo conozco por el vago recuerdo del oyente inmaduro que era yo (en aquel entonces), no me parecía ser dirigido tanto hacia esta única función como aquello que Heidegger más tarde presentó por primera vez en público en "La teoría de la verdad de Platón". Mis estudios sobre Platón me remitieron, por el contrario, cada vez más a los Diálogos dialécticos tardíos, y mi profundización en el Sofista me pareció más y más como una apertura de horizontes, en los cuales se presenta la cuestión del ser y el logos en sus diferentes facetas, pero que no puede ser vista como una mera etapa previa hacia la física aristotélica y la metafísica fundada en ella. En la dialéctica platónica hay, más bien, una perspectiva propia hacia la activación de la pregunta por el ser, que no culmina en la ontoteología de Aristóteles. No se debe ver, como Heidegger lo hiciera, el paso decisivo de Platón en el ajuste hacia el eidos, sino en la apertura hacia los logoi, en los cuales salen a la luz las relaciones entre las ideas. ${ }^{12}$

[368] Un Diálogo platónico siempre es polisémico y probablemente ninguno de los Diálogos platónicos lo es tanto como el Sofista. Todo el arte de Platón, como pensador, se encuentra ahí en su apogeo, en lo referente a la riqueza de las alusiones y en la admisión de las diversas interpretaciones. Se puede medir el efecto de un Diálogo platónico de esta índole, directamente, en la diversidad que generó la herencia platónica en el círculo de la Academia al cual pertenece, aunque no en último lugar, en la presencia avasalladora de la física y la metafísica aristotélicas. No me parece correcto ni posible querer deducir teorías unívocas susceptibles de una sola interpretación por

12 A mi entender, Whitehead tuvo algo similar en mente, cuando comprendió la relación como percepción -una "nota a pie de página de Platón". 
el mero estudio del Sofista y de los otros escritos conservados de Platón o de aquéllos de Aristóteles o hasta de la doxografía que agotan el impulso del Diálogo el Sofista. Lo que sí se puede constatar es el hecho de que también en la herencia de la Academia entra en juego la relación entre el logos y el ser que domina el Diálogo el Sofista.

Se puede reconocer el análisis del logos del Sofista y del concepto de la "methexis" cercano a dicho Diálogo en todos los testimonios que poseemos y, entenderlos a todos como los inicios de la prehistoria de la metafísica. Pero, a mi juicio, el lugar platónico de esta pregunta por el sentido del ser, de todos modos, no se deberá buscar en el concepto de sustancia de Aristóteles quien piensa en el ser de lo existente, el subiectum, al cual se refieren las predicaciones. Me parece llamar la atención sobre las relaciones más profundas, cuando el Visitante de Elea se basa en la verdad gramatical de que un enunciado no se consolida sino con el verbo. En esto reside un indicio importante, a saber, que el sentido de una información y, con ello, también el sentido del ser que ella presupone depende siempre del punto de vista desde el cual se observa y se trata lo existente. Sólo en esta referencia, a saber, un ఐpó $\varsigma \tau$, emerge el ser y, como sea, se perfecciona a través de su temporalidad. Cuando este Teeteto está sentado aquí, entonces, él es este hombre presente. Pero, simultáneamente, se entiende por esto que un hombre es capaz de estar sentado. Para saber esto, uno ni siquiera necesita conocer a Teeteto. La total amplitud del pensamiento del ser que comprende desde "éste-aquî" hasta su "ser-qué" entra ahí en juego, la cual ya determina la escritura de las categorías y ya está penetrada por los conceptos aristotélicos de la "dynamis" y la "energeia". La contingencia de lo particular nunca es, en efecto, palpable en el logos, pero el logos comprende también a ésta por el hecho de que dice "esto".

Existe una buena razón por la cual Aristóteles, en su uso del lenguaje, distingue el "ser" en el sentido de categorías y el "ser" en el sentido de energeia y dynamis; sin embargo, no separa al uno del otro. El motor de lo existente que se manifiesta en el logos, y el motor [369] de lo particular que se mantiene dentro del orden del movimiento de la naturaleza, están engarzados.

Esto se muestra, con claridad, en el análisis del libro $\Lambda$ de la Metafísica aristotélica. Ahí primero se explica, al detalle, la relación análoga entre la causa y lo causante y, después es superado por la constatación con tal de que haya, necesariamente, un existente superior que mantenga como motor inmóvil el orden íntegro del movimiento. El concepto aristotélico de la ontología termina, justamente, al reclamar como consecuencia la crítica de Espeusipo, el sucesor de Platón, que solamente uno puede ser el Señor. Incluso esto tiene en Platón una cierta correspondencia, bajo la 
condición de que Platón encuentre pensable el ser de lo fáctico, y no diferente, que a través de un Demiurgo, ${ }^{13}$ a la manera del Sofista (265c s.), del Filebo (28c ss.), del Timeo ( $30 \mathrm{~d}$ ss.). Aristóteles se burló acerca de esto diciendo que era una metáfora vacía; y, sin embargo, ya Teofrasto le tuvo que plantear la pregunta a Aristóteles mismo, si no acaso aquello que mueve, lo cual mueve a causa del ser amado, predispone el alma del amante. Precisamente, relativo a esto, pudimos encontrar, a través del Sofista, como se dijo más arriba, ciertas alusiones. El ser es, en su existente máximo, la personificación del movimiento puro y como lo existente por antonomasia ( $\tau$ ò $\varpi \alpha \nu \tau \varepsilon \lambda \tilde{\omega} \varsigma$ óv) es tanto la psique como el nous; sin embargo, es así como el ser siempre despide un resplandor pasajero tan sólo en el logos, el que siempre une a una idea con otra y la excluya de otra. Finalmente, se trata aquí de la tensión vital de nuestro pensar mismo, como creo haberlo reconocido cada vez más claramente a lo largo de mis estudios sobre los griegos. Lo divino que existe en todo, y el dios que separado de todo, mantiene todo en movimiento, son dos aspectos del ser que, como el platonismo o el aristotelismo, mantienen en estado de alerta todavía a todo el pensamiento de la metafísica hasta los tiempos modernos e incluso más allá.

Traducción: María Teresa Padilla Longoria REvisión: Hilde Rucker

\section{Referencias bibliográficas}

Benardete, Seth. (1984). The Being of Beautiful. The University of Chicago Press.

Hoffmann, Ernst. (1918). “Methesis y Metaxy en Platón”. En Tres escritos sobre la filosofía griega (pp. 29-51). Heidelberg.

Reeve, C. D. C. (1985). "Motion, Rest, and Dialectic in the Sophist", Archiv für Geschichte der Philosophie, 67(1), 47-64. https://doi.org/10.1515/agph.1985.67.1.47

13 Cf.también con La idea del Bien entre Platóny Aristóteles, en este mismo volumen, p. 216 s. 